\section{ESTUDO DA COMPOSIÇĀO MINERAL DE ALGUMAS PLANTAS FORRAGEIRAS ORIUNDAS DO ESTADO DO MATO GROSSO DO SUL. III - MANGANÉS}

FLÁVIO PRADA

Professor Livre Docente

Faculdade de Medicina Veterinária e Zootecnia da USP

MARIA AMELIA ZOGNO

Biologista

Faculdade de Medicina Veterinária e Zootecnia da USP

HÉLIO G.RUSSO

Médico Veterinário

Faculdade de Medicina Veterinária e Zootecnia da USP

\section{-FLORA ZYLBERKAN}

Biologista

Faculdade de Medicina Veterinária e Zootecnia da USP

JEFERSON IGNÁCIO DE ARAÚJO

Médico Veterinário

Faculdade de Medicina Veterinária e Zootecnia da USP

\section{CÁSSIO XAVIER DE MENDONÇA JÜNIOR}

Professor Livre Docente

Faculdade de Medicina Veterinária e Zootecnia da USP
PRADA, F.; ZOGNO, M.A.; RUSSO, H.G.; ZYLBERKAN, F. ARAUJO, J.I.; MENDONCCA JÜNIOR, C.X. Estudo da composiço mineral de algumas plantas forrageiras oriundas do Estado do Mato Grosso do Sul. III - Manganès. Rev.Fac. Mad.vet.Zootec. Univ.S.Pzulo, 20(1): 63-7, 1983.

RESUMO: Levantamento sobre a quantidade de manganès contida em quatro gramíneas - capim Coloniăo (Panicum maximun). Jaraguá (Hyparrhania rufa (Ness) Stapf), Pangola (Digitaria decumbens Stent) e capim Angolinha (Eriochloa polystachya (H.B.K.) Hitchc.) colhidas mensalmente durante um ano, no mu. niclpio de Brasilàndia, com área de 14.820 hectares em Mato Grosso do Sul. As medias anuais foram 190, 167, 811 e $494 \mathrm{ppm}$ para os capins, respectivamente, Colonião, Jaraguá, Pangola e Angolinha. O Pangola com a média 811 pom diferiu estatisticamente do Colonião, Jaraguá e Angolinha. Niveis tóxicos para bovinos foram apresentados pelos capins Pangoia \& Angolinha.

UNITERMOS: Manganes"; Plantas forrageiras*: Composição mineral

Trabalho apresentado no 17. Congresso Brasileiro de Medicina Veterinária, Fortaleza, 1980.
INTRODUÇĀO

Dados informativos sobre os teores de manganès nas pastagens, bem como as exigências na dieta dos animais, ou ainda, as variações estacionais deste elemento, são bastante escassos na literatura nacional.

Conquanto as plantas necessitem de reduzidas quantidades de manganès - associado ao cobre e zinco - para participar nos processos enzimáticos da célula vegetal, no organismo animal seu desempenho é bem grande. Além de ser ativador de várias enzimas, é essencial para a formação dos ossos, para a espermatogènese e oogènese. Nas fèmeas adultas, a carència do mineral retarda o ciclo estral, reduz a fertilidade e abortos e crias deformadas podem aparecer. Alterações nas patas, com várias defor. mações como torções do tarso e achatamento do estojo córneo dos cascos, e ainda diminuição no comprimento dos ossos que são fracos, podem surgir quando niveis de $\mathrm{Mn}$ na dieta são inferiores a $10 \mathrm{ppm}$, conforme UNDERWOOD 19 , DAVIS e LOOSLI5.

Altos niveis de manganès interferem na utilização do ferro e magnésio no soro sanguíneo, além de manter interrelação com o fósforo, de modo que o excesso de um prejudica o aproveitamento do outro, segundo MOREIRA 12. Por outro lado, niveis acima do normal em forrageiras são citados por alguns autores.

Assim, ANDREASI e colab. 2,3 relatam valores de cálcio, fósforo, ferro e manganès nos capins Colonião, Jaraguá e Gordura, em quatro tipos de solos e duas épocas do ano, em ấreas delimitadas do Estado de São Paulo. GAVILLON e QUADROS 9 estudaram, nas pastagens nativas do Rio Grande do Sul, os teores de manganès na primavera e verão.

GOMIDE e colab. 10 relatam valores de $\ddot{M}_{n}$ em plantas forrageiras, no municipio de Ituiutaba, em Minas Gerais. GALLO e colab. 8 , estudaram a composição mineral em 249 amostras de gramíneas e leguminosas, citando niveis tóxicos de $\mathrm{Mn}$ em várias regiões do Estado de São Paulo. AGOSTINI e KAMINSKI 1 apresentam dados de várias forrageiras colhidas na Região Central e em Campanha, no Rio Grande do Sul, durante a primavera de 1975 e ve$r$ ão de 1976, encontrando taxas de Mn consideradas acima do normal para animais em regime de pasto. FONSECA e LANG $^{7}$ relacionaram, na Costa Rica, altos níveis de $\mathrm{Mn}$ nas pastagens e pèlos, com a infertilidade de fêmeas bovinas. FICK e colab. 6 relatam, um grande número de observaçōes sobre minerais em forrageiras da América Latina.

O presente trabaiho faz parte de um plano de pesquisa tendente a estudar o problema relativo à nutrição mineral de bovinos em regime de pasto, revelando a quan. tidade e freque ència com que os animais consomem o mineral nas forragens, para se elucidar a atuação dos ele. mentos minerais como possiveis fatores de infertilidade. Alguns trabalhos de PRADA e colab. $\$ 5,16,17$, abordando o ferro, cálcio, fósforo e composição química, já se en contram publicados ou em fase de publicação. 


\section{MATERIAL E METODOS}

O material foi obtido na "Fazenda Très Barras", municipio de Brasilândia, Mato Grosso do Sul, com área de 14.820 hectares.

As plantas forrageiras existentes na região - Capim Colonião (Panicum maximum), Jaraguá (Hyparrhenia rufa, (Ness) Stapf), Pangola (Digitaria decumbens Stent), e Capim Angolinha (Eriochloa polystachya (H.B.K.) Hitchi). foram colhidas mensalmente, dentro de uma mesma área e no espaço de doze meses. Procurou-se, durante a fase experimental, evitar ao máximo as contaminações, coihendo-se amostras longe de estradas de rodagem ou cercas, evitando-se excrementos de animais e terra. As forragens, em sua parte anterior, eram cortadas com tesoura inox, ou mesmo colhidas com as mãos, acondicionadas em sa. cos plásticos, constituindo uma porção com cerca de 10 quilos aproximadamente de matéria úmida de várias partes dos pastos. O material era assim recolhido e enviado ao laboratório, sendo seco à temperatura de $65^{\circ} \mathrm{C}$ em estufa elétrica, com circulação de ar forçado.

As amostras foram digeridas por via "úmida", para micro elementos (tratamento com ácido nítrico concentra. do e perclórico a $70 \%$ ) como preconiza LAZAR 11 , e por via "seca", em forno mufla a $550^{\circ} \mathrm{C}$, para os macroelementos.

Para a determinação química foi empregado o método do periodato de sódio como agente oxidante, segundo (LAZAR "1).

As leituras foram efetuadas a $530 \mathrm{nn}$ em espectrofotômetro Zeiss Modelo PM Qll e cubas 100 QS.

A matéria mineral foi obtida conforme A.O.A.C. ${ }^{4}$.

Os indices pluviométricos foram anotados mensalmente, com a finalidade de se estabelecerem eventuais relações com as concentrações minerais dos capins.

$A$ análise estatística obedeceu ao modelo preconizado por SNEDECOR e COCHRAN 18, aplicando-se o teste de Newman-Keuls para contraste entre médias. Foi conven. cionado o nivel de significância de $5 \%$ para a interpretação estatística dos resultados. Dados complementares podem ser vistos em trabalhoanterior (PRADA e colab. 15).

\section{RESULTADOS}

Os niveis de manganês, expressos em partes por miIhão (ppm), verificados nas quatro gramíneas estudadas durante um ano, bem como o indice pluviométrico men. sal, estão contidos na Tab. 1.

São apresentadas ainda nesta tabela, as médias de Matéria Mineral obtidas e publicadas em pesquisa anterior ${ }^{15}$.

A análise de variância bem como o teste de Newman. Keuis se encontram na Tab. 2.

\section{DISCUSSĀO}

Nos relatos de FiCK e colab. 6 vamos encontrar que : porcentagem de determinação do elemento manganês para as forrageiras provenientes da América Latina, está ao redor de $11,2 \%$, e ainda destes, $21 \%$ situam-se na faixa de $0.40 \mathrm{ppm}$, enquanto $79 \%$ encontram-se acima de 40 $\mathrm{ppm}$. Se nos ativermos ao fato de que valores baixos - 10 ppm - como os citados por DAVIS e LOOSLI5, ou 40 ppm UNDERWOOD 19 ou ainda as recomendações do NRC 13.14 de 20 a 40 ppm, supririam as necessidades dos bovinos em pastoreio, quase todos os trabalhos citados em nossa literatura preencheriam os requisitos minimos para uma boa nutrição mineral.

No presente ensaio observamos que os niveis de $\mathrm{Mn}$ variaram de $75 \mathrm{ppm}$ (capim Jaraguá, dezembro) a 1.224 ppm (capim Pangola, abril). Houve diferenças significantes entre a média anual do capim Pangola ( $811 \mathrm{ppm})$ e as dos capins Angolinha (499 ppm), Colonião (190 ppm) e Jaraguá (167 ppm).

Se observarmos que UNDERWOOD 19 apresenta valores que vão de 8 a 100 ppm de $M n$ - média de 51 como normais em gramíneas, notamos que os nossos resultados, sem exceção, encontram-se acima da média. Por outro lado, DAVIS e LOOSLI5 relatam que niveis entre 20 e $70 \mathrm{ppm}$ atendem às exigências de crescimento normal e devem, portanto, figurar nos alimentos. Registra ainda, que para bovinos e ovinos o limite máximo da faixa de normalidade estaria ao redor de 150 ppm, e quantidades de 300 a 500 ppm, por períodos longos, poderão determinar prejuizo aos animais. No atual relato vemos que o capim Pangola, a exemplo do que ocorreu com oferro (PRADA e colab. 15), apresentou os valores mais elevados em abril (1224 ppm), maio (1111 ppm), junho (1018 ppm) e agosto (1092 ppm), tendo o valor mais baixo ocorrido em novembro, com (466 ppm).

Outro capim que apresentou valores elevados foi 0 Angolinha - (1012 ppm) em junho e (1031 ppm) em novembro - tendo o valor mais baixo (196 ppm) em abril. O Jaraguá apresentou os índices mais baixos, com média anual de $167 \mathrm{ppm}$ e intervalos de $75 \mathrm{ppm}$, em dezembro, a $290 \mathrm{ppm}$, em maio.

ANDREASI e colab. 3 encontraram uma tendència para maior concentração do eiemento na época das "secas", tendo o capim Colonião diferido estatisticamente do Jaraguá e Gordura, com valores de 326, 396 e 487 ppm os quais, por serem excessivamente elevados, podem causar danos à saúde e produtividade dos animais.

GAVILLON e QUADROS 9 em 154 amostras de pastagens nativas procedentes de 57 municipios do Rio Grande do Sul - primavera e verão - encontraram valores médios ao redor de 300 a 400 ppm, chamando a atenção - fato de não terem observado niveis abaixo de 100 ppm. Estes autores ainda levantam a possibilidade de carência de ferro, quando os valores de manganês se acham acima de 400 ppm.

Rev.Fac.Med.vet.Zootec.Univ.S.Paulo, 20(1): 63-7, 1983 
TABELA 1 - Niveis de Manganès em p.p.m. sobre a Matéria Seca, de capins provenientes de áreas do Mato Grosso do Sul. Indices pluviométricos em $\mathrm{mm}$ e médias de matéria mineral em porcentagem.

\begin{tabular}{|c|c|c|c|c|c|}
\hline Mès & Coloniðొ & Jaraguá & Pangola & Angolinha & $\begin{array}{l}\text { Chuva } \\
\text { em } \\
\mathrm{mm}\end{array}$ \\
\hline Dezembro & 152 & 75 & 505 & 298 & 176 \\
\hline Janeiro & 223 & 113 & 583 & 270 & 167 \\
\hline Fevereiro & 268 & 227 & 569 & 530 & 123 \\
\hline Março & 106 & 160 & 604 & 254 & 91.2 \\
\hline Abril & 109 & 167 & 1224 & 196 & 157,2 \\
\hline Maio & 93 & 290 & 1111 & 225 & 126,5 \\
\hline Junho & 101 & 170 & 1018 & 1012 & 116,5 \\
\hline Juiho & 382 & 192 & 822 & 443 & 68 \\
\hline Agosto & 191 & 145 & 1092 & 513 & 63 \\
\hline Setembro & 161 & 206 & 923 & 547 & $110^{\circ}$ \\
\hline Outubro & 309 & 136 & 818 & 673 & 126 \\
\hline Novembro & 185 & 124 & 466 & 1031 & 143 \\
\hline Média & 190 & 167 & 811 & 499 & 122,3 \\
\hline \multicolumn{6}{|l|}{ Matéria mi- } \\
\hline neral & 8,1 & 12.7 & 7,4 & 6,8 & \\
\hline
\end{tabular}

TABELA 2 - Análise de Variância e teste de Newman-Keuls, procedidos nos valores de Manganès.

\begin{tabular}{lrrrr}
\hline $\begin{array}{l}\text { Fontes } \\
\text { de } \\
\text { Variaçao }\end{array}$ & G.L. & S.O. & O.M. & F \\
\hline Capins & 3 & 3.314 .389 .9 & $1.104 .796,6$ & $27,1 \cdot(2,82)$ \\
Residuo & 44 & $1.791 .029,8$ & $40.705,2$ & \\
Total & 47 & $5.105 .419,7$ & & \\
\hline
\end{tabular}

- $\mathrm{P}<0,05$

\begin{tabular}{lllll} 
Newman-Keuis & Jaragua & Coloniło & Angolinha & Pangola \\
& $\bar{x}=167$ & $\bar{x}=190$ & $\bar{x}=499$ & $\bar{x}=811$ \\
& $p p m$ & $p p m$ & $p p m$ & $p p m$ \\
\hline
\end{tabular}

\begin{tabular}{lrrr}
\hline Jaraguá & - & & \\
Coloniảo & 22,9 ns & - & - \\
Angollnha & $331,99^{\circ}$ & 309,0 & - \\
Pangola & $644,1^{*}$ & $621,2{ }^{*}$ & $312,2 \cdot$ \\
\hline
\end{tabular}

- Signiflcante

$\mathrm{ns}=\mathrm{N}$ ão significante

$\bar{x}=$ Media aritmetica

Na presente pesquisa encontramos em 19 amostras de capins Pangola e Angolinha, teores acima de 400 ppm. Para o Pangola, valores encontrados durante os doze meses ultrapassaram 400 ppm, enquanto para o Angolinha, em cinco amostras, o indice foi inferior a $400 \mathrm{ppm}$.

GOMIDE e cols 10 apresentam o manganès, em cortes sucessivos de gramineas, com valores da ordem de 176 a 257 ppm, considerados elevados. Concluem ainda que tais cifras são extremamente aitas em relação à média da maioria dos volumes, excedendo em muito o limite máximo (10 ppm) considerado necessário para a alimenta६ão do gado de corte.

GALLO e colab. 8 demonstraram que $8 \%$ das gramineas continham manganès acima de $300 \mathrm{ppm}$ em pastagens de Colonião. Outros valores, também elevados, foram encontrados nos capins Jaraguá (285 ppm). Pangola (519 $\mathrm{ppm})$ e Elefante (337 ppm), concluindo que alguns minerais como $\mathrm{Ca}, \mathrm{K}, \mathrm{Mg}, \mathrm{Fe}$ e $\mathrm{Mn}$ mostraram-se sempre acima do minimo para a adequada nutrição do gado.

AGOSTINI e KAMINSKI 1 apresentaram concentraç̃̃es médias de $M n$ nas pastagens de 221 a 608 ppm as quais foram superiores aos achados por GOMIDE e colab.10 e ANDREASI e colab. ${ }^{3}$, porém abaixo da faixa do presente estudo. ANDREASI e colab. 3 também concluem que os teores de manganês, encontrados nos pastos, estão acima do limite normal de tolerância, podendo acarretar transtornos não só na produção vegetal como também ao organismo animal.

O conteúdo de manganês nas forragens e sua relação com os níveis encontrados nos pélos e seus reflexos na reprodução de bovinos, levaram FONSECA e LANG? a pesquisarem durante 5 anos os efeitos em 751 vacas na região do $V$ ale de Orosi na Costa Rica. Os indices mais baixos foram encontrados no Pennisetum purpureum (34 ppm) enquanto os mais elevados estiveram com o Cyperus niger $(665 \mathrm{ppm})$. De modo geral, estes valores foram inferiores aos achados na presente pesquisa.

Ainda no que se refere a correlação pélos/forragem, ficou demonstrado que os niveis nos pêlos aumentam a medida que a forragem possui taxas mais elevadas. Assim, na granja que apresentava valores no pasto de $210 \mathrm{ppm}$ de manganès, os pèlos dos animais continham 91 ppm. Forragem com $130 \mathrm{ppm}$ os animais apresentavam 73 nos pélos. Por último, valores de $74 \mathrm{ppm}$ nos tecidos vegetais, correspondiam a $18 \mathrm{ppm}$ nos pèlos. Estes autores 7 concluem que a taxa de manganês na forragem refletiu - no conteúdo deste elemento nos pêlos das vacas, sendo observado um efeito direto entre o alto conteúdo de manganès na forragem, sua concentração nos pélos e a significância que ambos os fatores tem na baixa eficiència reprodutiva destes animais. A porcentagem de partos nas granjas estudadas durante os 5 anos, esteve respectivamente entre $57,8 \%$ e $64,2 \%$; o intervalo entre partos foi maior e o número de bezerros desmamados foi menor que na granja cujos valores em manganès apresentava 74 ppm na forragem e 18 ppm nos pélos. 
As observações de trabalhos anteriores de ANDREASI e colab. ${ }^{3}$ e PRADA e colab. 15,16 nos levam a suspeitar de uma interação entre o $\mathrm{Fe}, \mathrm{Mn}$ e outro elemento importante na fisiologia vegetal e animal que é o fósforo. Sabemos que 0 manganês, em niveis elevados no solo, pode ser absorvido pelas gramíneas em níveis até tóxicos, dependendo do $\mathrm{pH}$ do solo ou mesmo da variedade de planta que extrai este mineral. Os achados de ANDREASI e colab. 3 de que o capim Gordura (Melinis minutiflora) é uma gramínea "extratora" de ferro, nos levaram a observar o comportamento destes vegetais em diferentes áreas e a comparar com os valores do elemento fósforo, considerado elemento carente mais importante em grandes áreas do País. Assim, na presente pesquisa notamos que - Pangola com a média de 811 ppm de Mn teve 476 ppm de ferro (PRADA e colab. ${ }^{15}$ ) e 0,09\% de fósforo (PRADA e colab. ${ }^{16}$ ). No Quadro 1 podemos observar que os valores encontrados em São Paulo para os três capins, exceção do Gordura, estiveram em faixa considerada normal, tanto para o elemento manganês como o ferro, sem reflexos aparentes nos níveis de fósforo. No presente experimento os capins com mais altos valores em manganês apresentaram médias mais baixas de fósforo. Outras pesquisas, levando em consideração também a parte reprodutiva dos rebanhos, deverão esclarecer a importância da interação $\mathrm{Fe}, \mathrm{Mn}$ e $\mathrm{P}$ nas forragens, sobre a nutrição mineral do gado em regime de pasto. Os índices pluviométricos. não forneceram dados para comparação, com os valores obtidos por ANDREASI e colab. 3 e GALLO e colab. 8 .

QUADRO 1 - Variações individuais em áreas delimitadas de São Paulo e Mato Grosso do Sul.

São Paulo

(Duas épocas do ano) *

\begin{tabular}{|c|c|c|c|c|c|c|}
\hline & \multicolumn{2}{|c|}{$\begin{array}{c}\text { Médias } \\
\text { Manganès ppm }\end{array}$} & \multicolumn{2}{|c|}{$\begin{array}{l}\text { Médias } \\
\text { Ferro ppm }\end{array}$} & \multicolumn{2}{|c|}{$\begin{array}{c}\text { Médias } \\
\text { Fósforo (\%) }\end{array}$} \\
\hline & secas & águas & secas & águas & secas & águas \\
\hline Colonião & 226 & 146 & 119 & 95 & 0,10 & 0,18 \\
\hline Jaraguá & 158 & 139 & 162 & 141 & 0,08 & 0,13 \\
\hline Gordura & 142 & 147 & 402 & 301 & 0,10 & 0,18 \\
\hline
\end{tabular}

* ANDREASI e colab. 3
Mato Grosso do Sul

(Média Anual) *

\begin{tabular}{l|c|c|c}
\hline Capins & $\begin{array}{c}\text { Manganês } \\
\text { ppm }\end{array}$ & $\begin{array}{c}\text { Ferro } \\
\text { ppm }\end{array}$ & Fósforo (\%) \\
\hline Colonião & 190 & 131 & 0,19 \\
Jaraguá & 167 & 311 & 0,13 \\
Pangola & 811 & 476 & 0,09 \\
Angolinha & 499 & 258 & 0,10 \\
\hline
\end{tabular}

* PRAda e colab. 15,16

\section{CONCLUSÕES}

Face aos resultados encontrados no presente trabalho, parece lícito concluir que:

1 - os niveis médios de manganês nas quatro gramí. neas estudadas estiveram acima das necessidades para a nutrição de bovinos em regime de pasto;

2 - os capins Pangola (Digitaria decumbens Stent) e Angolinha. (Eriochloa polystachya (H.B.K.) Hitchi) apresentaram valores que são considerados tóxicos para os animais;

3 - a média anual de manganês no capim Pangola diferiu estatisticamente dos demais capins.

PRADA, F.; ZOGNO, M.A.; RUSSO, H.G.; ZYLBERKAN, F.; ARAÚJO, J.I.; MENDONÇA JÜNIOR, C.X. Study of the mineral composition of some forage plants from areas of Mato Grosso do Sul State - Brazil. III. Manganese. Rev.Fac. Med.vet.Zootec.Univ.S.Paulo, 20(1):63-7, 1983.

SUMMARY: It was conducted a study about the manganese content of Guinea grass (Panicum maximun), Jaraguá grass (Hyparrhenia rufa (Ness) Stapf), Pangola grass (Digitaria decumbens, Stent) and Angolinha grass (Eriochloa polystachya (H.B.K.) Hitchc). Collected (14.820 h.) in areas of the State of Mato Grosso do Sul, Brazil. Sample analisis examined showed in the Guinea grass, Jaraguá grass, Pangola grass and Angolinha grass, 190, 167, 811 e 499 ppm of manganese respectively. The Pangola grass exhibited significantly higher concentrations of manganese ( 811 ppm) than Angolinha grass (499 ppm), Guinea grass (190 ppm) or Jaraguá grass (167 ppm). High levels of manganese in Pangola grass and Angolinha grass were found to be toxic for cattle.

UNITERMS: Forages*; Manganese*; Mineral elements
1 - AGOSTINI, J.A.E. \& KAMINSKI, J. Estudo preliminar das concentrações de nutrientes minerais de solos e pastagens naturais ocorrentes em diferentes regiões do Rio Grande do Sul. Rev. Cent.Ci.Rurais, 6: 385-406, 1976.
2 - ANDREASI, F.; VEIGA, J.S.M.; MENDONÇA JR., C.X.; PRADA, F.; BARNABE, R.C. Levantamento dos elementos minerais em plantas forrageiras de áreas delimitadas do Estado de São Paulo. I - Cálcio, fósforo e magnésio. Rev. 
Fac.Med.vet., São Paulo, 7: 583-604, 1966/67.

3 - ANDREASI, F.; VEIGA, J.S.M.; PRADA, F.; MEN. DONÇA JÚNIOR, C.X. Levantamento dos elementos minerais em plantas forrageiras de áreas delimitadas do Estado de São Paulo. III - Ferro e Manganès. Rev.Fac.Med.vet., São Paulo, 7: 857-70, 1968.

4 - ASSOCIATION OF OFFICIAL AGRICULTURAL CHEMISTS. Official and tentative methods of analysis. 6.ed. Washington, 1945.

5 - DAVIS, G.K. \& LOOSLI, J.K. Mineral metabolism (animal). Ann.Rev.Biochem., 23: 459-80, 1954.

6 - FICK, K.R.; MCDOWELL, L.R.; HOUSER, R.H.; SILVA, H.M. Atual pesquisa de minerais na América Latina. In: SIMPÓSIO LATINO AME. RICANO DE PESQUISAS EM NUTRIÇĀO MINERAL DE RUMINANTES EM PASTA. GENS, Belo Horizonte, 1976. p. 294-5.

7 - FONSECA. H. \& LANG, C. Contenido de manganeso em los forrajes del $V$ alle de Orosi $y$ su efecto sobre la concentracion em el pelo y la reproducción em vacas lecheras. In: SYMPOSIUM ON NUCLEAR TECHNIQUES IN ANIMAL PRODUCTION AND HEALTH, Wien, 1976. Proceedings. (I.A.E.A., SM-205).

8- GALLO, J.R.; HIROCE, R.; BATAGLIA, O.C.; FURLANI, P.R.; FURLANI, A.M.C.; MATTOS, H.B.; SARTINI, H.J.; FONSECA, M.P. Composição química inorgânica de forrageiras do estado de São Paulo. Bol. Indúst.anim., 31: 115-37, 1974.

9 - GAVILLON, O.\& QUADROS, A.T. O ferro e o manganês em pastagens nativas do Rio Grande do Sul. Pesq.Agropec.bras.Sér.Zootec., 8: 47:54, 1973.

10 - GOMIDE, J.A.; CRISTMAS, E.P.; GARCIA, R.; PAULA, R.R. Competição de gramineas forrageiras para corte em um latossolo vermelho distrófico sob vegetação de cerrado do Triàngulo Mineiro. Rev.Soc.Bras.Zootec., 3: 191-209, 1974.
11 - LAZAR, V.A. Methods for the determination of mineral elements in plant tissue. S.L.P., U.S. Plant, Soil and Nutrition Laboratory, s.d. p. 1.32 .

12 - MOREIRA, C.R. Mineralização correta, uma ciência e uma arte. Anu. bras. Med.vet., p. 6-19, 1978/ 79.

13 - NATIONAL RESEARCH COUNCIL. 4. Nutrient requiremerts of beef cattle. Washington, 1970.

14 - NATIONAL RESEARCH COUNCIL. 3. Nutrient requirements of dairy cattle. Washington, 1971.

15 - PRADA, F.; RUSSO, H.G.; ZYLBERKAN, F.; ARAUJO, J.I.; MENDONÇA JUNIOR, C.X.; ZOGNO, M.A. Estudo da composição mineral de algumas plantas forrageiras oriundas do estado de Mato Grosso do Sul. II - Ferro. Rev. Fac.Med.vet.Zootec.Univ.S.Paulo, 18: 123-29, 1981.

16 - PRADA, F.; ZOGNO, M.A.; MENDONÇA JÜNIOR, C.X.; RUSSO, H.G.; ARAUJO, J.I.; ZYLBER. KAN, F. Estudo da composição mineral de algumas plantas forrageiras oriundas do estado do Mato Grosso do Sul. I - Cálcio e fósforo. Rev.vet.bras., São Paulo, 1(1) 1983. (No prelo)

17 - PRADA, F.; ZOGNO, MA.; MENDONCCA JUNIOR, C.X.; RUSSO, H.G.; ARAUJO, J.I.; ZILBERKAN, F. Composição quimica de algumas plantas forrageiras oriundas do estado de Mato Grosso do Sul. Rev.Fac.Med.vet.Zootec.Univ. S.Paulo, 21(1) 1984. (No prelo)

18 - SNEDECOR, G.W. \& COCHRAN, W.G. Statistical methods. 6. ed. Ames, lowa State University Press, 1967.

19 - UNDERWOOD, E.J. Trace elements in human and animal nutrition. 2. ed. New York, Academic Press, 1969.

Recebido para publicação em : 20-10-1982. Aprovado para publicação em: 24-06-1983. 